\title{
Endocrine Function Following Acute SAH
}

\author{
Paul Vespa - The Participants in the International Multi-disciplinary \\ Consensus Conference on the Critical Care Management of Subarachnoid Hemorrhage
}

Published online: 2 August 2011

(C) Springer Science+Business Media, LLC 2011

\begin{abstract}
Disruption of the hypothalamic-pituitaryadrenal axes may occur after aneurysmal subarachnoid hemorrhage, resulting in hypopituitarism. An electronic literature search was conducted to identify articles with English-language abstracts published between 1980 and March 2011, which addressed hypothalamic-pituitaryadrenal axis insufficiency and hormone replacement. A total of 18 observational and prospective, randomized studies were selected for this review. Limited data are available, evaluating pituitary effects during the acute stage after subarachnoid hemorrhage, with inconsistent results being reported. Overall, after acute subarachnoid hemorrhage, cortisol levels may initially be supranormal, decreasing toward normal levels over time. During the months to years after subarachnoid hemorrhage, pituitary deficiency may occur in one out of three patients. Limited data suggest modest outcome benefits with fludrocortisone and no benefit or harm from corticosteroids.
\end{abstract}

The Participants in the International Multi-disciplinary Consensus Conference: Michael N. Diringer, Thomas P. Bleck, Nicolas Bruder, E. Sander Connolly, Jr., Giuseppe Citerio, Daryl Gress, Daniel Hanggi, J. Claude Hemphill, III, MAS, Brian Hoh, Giuseppe Lanzino, Peter Le Roux, David Menon, Alejandro Rabinstein, Erich Schmutzhard, Lori Shutter, Nino Stocchetti, Jose Suarez, Miriam Treggiari, MY Tseng, Mervyn Vergouwen, Paul Vespa, Stephan Wolf, Gregory J. Zipfel.

\section{P. Vespa $(\bowtie)$}

Division of Neurosurgery, David Geffen School of Medicine at UCLA, University of California, Room 6236A Ronald Reagan UCLA Medical Center, 750 Westwood Blvd, Los Angeles, CA 90095, USA

e-mail: PVespa@mednet.ucla.edu
Keywords Adrenal insufficiency · Adrenocorticotropic hormone - Cortisol . Growth hormone $\cdot$ Hypothalamic

\section{Introduction}

Aneurysmal subarachnoid hemorrhage (SAH) presents with widespread medical complications that include disruption of the hypothalamic-pituitary-adrenal (HPA) axis. Sodium imbalance in SAH related to the syndrome of inappropriate antidiuretic hormone secretion or cerebral salt wasting syndrome is addressed elsewhere (see Chapter Hyponatremia). Hypopituitarism may occur following brain injury, including after SAH [1-3]. An initial surge in the sympathetic nervous system is associated with the release of catecholamines and cortisol. Dysfunction of the HPA can result in acute physiological problems in the critical care setting and potentially in long-lasting effects on cognitive outcome after SAH [4, 5].

This study was designed to evaluate the incidence and consequences of HPA insufficiency in patients with SAH. The literature was also reviewed for investigating whether acute hormonal replacement therapy is beneficial for the $\mathrm{SAH}$ patient, including the use of corticosteroids for the purpose of enhancing hemodynamic and cognitive outcomes.

\section{Methods}

An electronic literature search was performed by conducting a PubMed survey for articles published from 1980 to March 2011. Candidate articles were identified using the keywords "subarachnoid hemorrhage," "pituitary," "hypothalamus," "corticosteroids," "adrenal insufficiency," "outcomes," 
and "mortality." Titles and abstracts from initially identified citations were reviewed for relevance to the topic of pituitary dysfunction in patients with aneurysmal SAH and study design. Articles were included if they described original research involving human subjects and were designed as observational or randomized trials and the abstract was available in English. Selected studies were evaluated using the GRADE system for quality [6].

\section{Summary of the Literature}

A total of 206 articles were initially identified as potential candidate articles. From these, 38 original research studies were identified, with 18 observational and prospective, randomized studies being selected for this review.

\section{Incidence of HPA Insufficiency}

Several prospective observational studies have been performed to document the incidence of dysfunction of the
HPA axes, primarily through prospective measures of individual hormonal concentrations in the acute and chronic setting (Table 1 [4, 7-16]). Unfortunately, most studies focus on the chronic setting from 12 to 72 months after SAH. In the chronic setting, the prevalence of a cortisol deficiency ranges from 2.5 to $40 \%$ of patients. Another study showed endocrine dysfunction in nearly half of the 30 patients evaluated 12-24 months after SAH (47\%), with cortisol hyporesponsiveness to the low-dose corticotropin stimulation test in $10 \%$ [17]. A small study sampling 14 patients after SAH and 15 matched controls identified sympathetic activation with 3-4 times increased norepinephrine spillover to plasma, 2-7 days after $\mathrm{SAH}$ [18].

Six studies evaluated the HPA in acute SAH [7, 9-11, 13, 16]. Deficiencies in adrenocorticotropic hormone (ACTH) and stimulation-induced elevation in cortisol were found in acute SAH by Kelly and colleagues [7] and Dimopoulou and colleagues [10], whereas normal cortisol was found by Savaridas. Bendel et al. [11] documented that $\mathrm{ACTH}$ and cortisol values were higher in the acute $\mathrm{SAH}$

Table 1 HPA disorders after SAH

\begin{tabular}{|c|c|c|c|c|}
\hline Study & Time after SAH & HPA abnormality & Impact on outcome & GRADE criteria \\
\hline Kelly et al. [7] & Acute & Pituitary deficiency: TRH, ACTH & Outcome not studied & $\begin{array}{l}\text { Low-too small } \\
\quad(n=2)\end{array}$ \\
\hline $\begin{array}{l}\text { Kreitschmann-Andermahr } \\
\text { et al. [8] }\end{array}$ & $12-60$ months & Pituitary deficiency: ACTH, GH & Outcome not studied & Low-chronic \\
\hline Savaridas et al. [9] & Acute & Normal ACTH, cortisol levels & Outcome not studied & $\begin{array}{l}\text { Low-too small } \\
\quad(n=6)\end{array}$ \\
\hline $\begin{array}{l}\text { Kreischmann-Andermahr } \\
\text { et al. [4] }\end{array}$ & $12-72$ months & Pituitary deficiency: ACTH, TRH, GH & No effect on outcome & Moderate-chronic \\
\hline Dimopoulou et al. [10] & Acute & $\begin{array}{l}\text { Pituitary deficiency: ACTH, deficient } \\
\text { stimulation of cortisol }\end{array}$ & $\begin{array}{l}\text { Worse outcome in } \\
\text { relative adrenal } \\
\text { insufficiency }\end{array}$ & Low-acute \\
\hline Bendel et al. [11] & $\begin{array}{l}\text { Acute followed } \\
\text { by chronic }\end{array}$ & Supranormal ACTH and cortisol & $\begin{array}{l}\text { No effect on outcome; } \\
\text { normalization ACTH } \\
\text { and cortisol by } \\
3 \text { months }\end{array}$ & Moderate-acute \\
\hline Aimaretti et al. [12] & 12-60 months & Pituitary deficiency: ACTH, GH & No effect on outcome & Low-acute \\
\hline Weant et al. [13] & Acute & $\begin{array}{l}\text { Relative adrenal insufficiency in } \\
\text { pressor unresponsive patients only }\end{array}$ & Outcome not studied & Moderate-acute \\
\hline Srinivasan et al. [14] & 5-12 months & $\begin{array}{l}\text { Pituitary deficiency: GH; adrenal } \\
\text { insufficiency }\end{array}$ & $\begin{array}{l}\text { Effect on functional } \\
\text { outcome using } \\
\text { 18-item Functional } \\
\text { Independence } \\
\text { Measure score }\end{array}$ & Moderate-chronic \\
\hline Lammert et al. [15] & $3-6$ months & $\begin{array}{l}\text { Pituitary deficiency varied, but low } \\
\text { prevalence overall }\end{array}$ & No effect on outcome & Moderate-chronic \\
\hline Poll et al. [16] & Acute & $\begin{array}{l}\text { Supranormal to normal cortisol levels; } \\
\text { no low levels found. Variable } \\
\text { ACTH levels; abnormal diurnal } \\
\text { variation }\end{array}$ & No effect on outcome & Moderate-acute \\
\hline
\end{tabular}

$A C T H$ adrenocorticotropic hormone, $G H$ growth hormone, $T R H$ thyrotropin-releasing hormone 
patients than in age-matched controls. The degree of cortisol elevation was not associated with the severity of SAH. In contrast, mixed results of normal cortisol with low or normal levels of ACTH were found by Poll et al. [16]. In the latter study, the diurnal variation of free cortisol levels was abnormal in some SAH patients, and correlated with poor outcome and longer length of stay compared with those patients with normal diurnal variation. High levels of cortisol have recently been associated with delayed cerebral ischemia, although the causality of this observation is unclear [19]. Overall, there is a paucity of evidence that significant HPA dysfunction occurs in the acute phase of illness in most SAH patients. Most studies either did not study the effect of HPA dysfunction on outcome or could find no specific effect on outcome.

In contrast, a recent study of a particular subgroup of SAH patients who exhibit vasopressor-resistant hypotension suggests that relative adrenal insufficiency may occur [13]. In the latter observational, convenience sample study, $18 \%$ of SAH patients were found to have vasopressorresistant blood pressures during the induction of hypertensive therapy. In that subgroup, $69 \%$ were found to have relative adrenal insufficiency, as defined by a positive response to the cosyntropin stimulation test. This latter study suggests that there may be an important subgroup of patients with relative adrenal insufficiency requiring hormonal replacement therapy with hydrocortisone to assist with inducing therapeutic hypertensive therapy.

\section{Hormonal Replacement Therapy for SAH}

There are very few prospective studies, evaluating the influence of hormonal replacement therapy on SAH. There have been two prospective studies on the use of fludrocortisone [20, 21], one on hydrocortisone [22], and one on methylprednisolone [23]. Treatment with fludrocortisone was weakly associated with decreased delayed cerebral ischemia (RR 0.65 ; 95\% CI 0.33-1.27) and lower mortality (RR $0.33 ; 95 \%$ CI 0.03-3.20). The wide confidence intervals highlight the modest effects of this treatment. Mineralocorticoids are frequently used in the treatment of hyponatremia, which is discussed in the Hyponatremia Chapter.

The use of corticosteroids has been sparsely studied as well. In the single trial of hydrocortisone, there was an increased one-month mortality rate (RR $1.49 ; 95 \%$ CI $0.85-2.61$ ) and higher incidence of hyperglycemia [23 as discussed in 25]. The recent study by Gomis et al. [23] was a single-center, randomized, controlled trial of high-dose methylprednisolone $(18 \mathrm{mg} / \mathrm{kg} /$ day for 3 days $)$ in 95 patients with SAH. In this study, patients exposed to methylprednisolone experienced a similar incidence of key outcome variables as compared with the placebo group, including symptomatic vasospasm ( 28 vs $31.5 \%, P<0.7)$, modified Rankin Scores at 12 months $(P<0.08)$, delayed ischemic neurologic deficits on imaging (24.4 vs $18.4 \%$, $P<0.8$ ), and death (18.3 vs $17.3 \%, P<0.8)$. Gomis et al. highlight that functional outcome, determined using a modified version of the Rankin Scores, which excludes all patient deaths, was better in the methylprednisolone group. This form of analysis is unprecedented in similar outcome trials, and hence, the conclusions based on this analysis cannot be taken at face value. In summary, the existing data suggest that effect of corticosteroid replacement ranges from harmful to no benefit in outcome [24].

\section{Conclusions}

In acute $\mathrm{SAH}$, there is a disruption of the diurnal variation of the HPA, with initially supranormal cortisol levels that decrease to normal or near-normal concentrations over time. During the chronic period lasting months to years after $\mathrm{SAH}$, a deficiency in pituitary function appears to exist in one-fourth to one-third of patients. The replacement of mineralocorticoid function using fludrocortisone may convey a weak beneficial effect at best. Corticosteroids replacement using hydrocortisone or methylprednisolone may be harmful or, at best, ineffective.

\section{References}

1. Giordano G, Aimaretti G, Ghigo E. Variations of pituitary function over time after brain injuries: the lesson from a prospective study. Pituitary. 2005;8:227-31.

2. Schneider HJ, Kreitschmann-Andermahr I, Ghigo E, Stalla GK, Agha A. Hypothalamopituitary dysfunction following traumatic brain injury and aneurysmal subarachnoid hemorrhage: a systematic review. JAMA. 2007;298:1429-38.

3. Gasco V, Prodam F, Pagano L, et al. Hypopituitarism following brain injury: when does it occur and how best to test? Pituitary. 2010 (in press).

4. Kreitschmann-Andermahr I, Hoff C, Saller B, et al. Prevalence of pituitary deficiency in patients after aneurysmal subarachnoid hemorrhage. J Clin Endocrinol Metab. 2004;89:4986-92.

5. Kagerbauer SM, Rothoerl RD, Brawanski A. Pituitary dysfunction after aneurysmal subarachnoid hemorrhage. Neurol Res. 2007;29:283-8.

6. Atkins D, Best D, Briss PA, et al. Grading quality of evidence and strength of recommendations. BMJ. 2004;328:1490.

7. Kelly DF, Gonzalo IT, Cohan P, Berman N, Swerdloff R, Wang C. Hypopituitarism following traumatic brain injury and aneurysmal subarachnoid hemorrhage: a preliminary report. J Neurosurg. 2000;93:743-52.

8. Kreitschmann-Andermahr I, Hoff C, Niggemeier S, et al. Pituitary deficiency following aneurysmal subarachnoid haemorrhage. J Neurol Neurosurg Psychiatry. 2003;74:1133-5.

9. Savaridas T, Andrews PJ, Harris B. Cortisol dynamics following acute severe brain injury. Intensive Care Med. 2004;30:1479-83.

10. Dimopoulou I, Tsagarakis S, Kouyialis AT, et al. Hypothalamicpituitary-adrenal axis dysfunction in critically ill patients with traumatic brain injury: incidence, pathophysiology, and 
relationship to vasopressor dependence and peripheral interleukin-6 levels. Crit Care Med. 2004;32:404-8.

11. Bendel S, Koivisto T, Ruokonen E, et al. Pituitary-adrenal function in patients with acute subarachnoid haemorrhage: a prospective cohort study. Crit Care. 2008;12:1-10.

12. Aimaretti G, Ambrosio MR, Di Somma C, et al. Traumatic brain injury and subarachnoid haemorrhage are conditions at high risk for hypopituitarism: screening study at 3 months after the brain injury. Clin Endocrinol. 2004;61:320-6.

13. Weant KA, Sasaki-Adams D, Dziedzic K, Ewend M. Acute relative adrenal insufficiency after aneurysmal subarachnoid hemorrhage. Neurosurgery. 2008;63:645-9.

14. Srinivasan L, Roberts B, Bushnik T, et al. The impact of hypopituitarism on function and performance in subjects with recent history of traumatic brain injury and aneurysmal subarachnoid haemorrhage. Brain Inj. 2009;23:639-48.

15. Lammert A, Bode H, Hammes HP, et al. Neuro-endocrine and neuropsychological outcome after aneurysmal subarachnoid hemorrhage (aSAH): a prospective cohort study. Exp Clin Endocrinol Diabetes. 2011;119:111-6.

16. Poll EM, Boström A, Bürgel U, et al. Cortisol dynamics in the acute phase of aneurysmal subarachnoid hemorrhage: associations with disease severity and outcome. J Neurotrauma. 2010;27:189-95.

17. Dimopoulou I, Kouyialis AT, Tzanella M, et al. High incidence of neuroendocrine dysfunction in long-term survivors of aneurysmal subarachnoid hemorrhage. Stroke. 2004;35:2884-9.
18. Naredi S, Lambert G, Friberg P, et al. Sympathetic activation and inflammatory response in patients with subarachnoid haemorrhage. Intensive Care Med. 2006;32:1955-61.

19. Vergouwen MD, van Geloven N, de Haan RJ, Kruyt ND, Vermeulen M, Roos YB. Increased cortisol levels are associated with delayed cerebral ischemia after aneurysmal subarachnoid hemorrhage. Neurocrit Care. 2010;12:342-5.

20. Hasan D, Lindsay KW, Wijdicks EF, et al. Effect of fludrocortisone acetate in patients with subarachnoid hemorrhage. Stroke. 1989;20:1156-61.

21. Mori T, Katayama Y, Kawamata T, Hirayama T. Improved efficiency of hypervolemic therapy with inhibition of natriuresis by fludrocortisone in patients with aneurysmal subarachnoid hemorrhage. J Neurosurg. 1999;91:947-52.

22. Hashi K, Takakura K, Sano K, Ohta T, Saito I, Okada K. Intravenous hydrocortisone in large doses in the treatment of delayed ischemic neurological deficits following subarachnoid hemorrhage_-results of a multi-center controlled double-blind clinical study. No To Shinkei. 1988;40:373-82.

23. Gomis P, Graftieaux JP, Sercombe R, Hettler D, Scherpereel B, Rousseaux P. Randomized, double-blind, placebo-controlled, pilot trial of high-dose methylprednisolone in aneurysmal subarachnoid hemorrhage. J Neurosurg. 2010;112:681-8.

24. Feigin VL, Anderson N, Rinkel GJ, Algra A, van Gijn J, Bennett DA. Corticosteroids for aneurysmal subarachnoid haemorrhage and primary intracerebral haemorrhage. Cochrane Database Syst Rev. 2005;3:CD004583. 